\title{
Fabrication and performance analysis of concentrated hybrid photovoltaic system
}

\author{
Krishna Murthy ${ }^{1 *}$, Ajay Daniel ${ }^{1}$, Lanvin Concessao ${ }^{1}$, Habbie Alex Roy ${ }^{1}$ and \\ Ganesha A. ${ }^{1}$ \\ ${ }^{1}$ Department of Mechanical and Manufacturing Engg, MIT, Manipal Academy of Higher \\ Education, Manipal- 576104, India
}

\begin{abstract}
Sun is the most important source of renewable source of energy. During the past few decades there has been an everincreasing interest in Photovoltaic (PV) cells as it directly converts solar radiation into electricity. This paper involves the performance study of photovoltaic system under concentrated solar radiation. The main problem with the concentration solar energy is the drastic increase in temperature of the photovoltaic module resulting in a decrease in performance efficiency of the system. This problem of overheating of the system can be overcome by providing cooling which would ensure operation of the module in the optimal temperature range. Hence, the setup would function as a hybrid model serving the dual purpose of power generation while also utilizing the waste heat for water heating applications. The experimental set up consist of a novel arrangement of concentrator and reflector and the cooling system. The Hybrid Photovoltaic System was repeatedly tested under real time conditions on several days. A comparison was drawn between the results obtained from direct exposure of a standard photovoltaic module to that obtained from the hybrid system in order to better understand the improvement in performance parameters. The study shown a significant improvement of output of standard photovoltaic module under the concentrated solar radiation.
\end{abstract}

Keywords: Renewable energy, concentrated photovoltaics, Photovoltaic/Thermal hybrid systems, P V module

\section{Introduction}

Energy is the basic requirement of any civilised society. Renewable energy is the theme of the 21 st century. At a time when the world is debating over the use of fossil fuels to generate electricity, it stands united on the idea of implementing sustainable technologies to reduce the carbon footprint. Sun without any doubt is one of the most important sources of energy that we can make use of in our endeavour to achieve our

* Corresponding author: krishna.murthy@manipal.edu 
targets of sustainability. Natural gas will give out first, then petroleum, and finally coal. As long as coal is available, it can be converted into gas and oil from the available technology. Some European countries are already feeling the pinch of dwindling fuel supplies. Photovoltaic Technology has come a long way ever since its discovery in 1839 by A. E. Becquerel [1]. They have become a well-established source of energy with them being used in all the imaginable ways. Monocrystalline and polycrystalline Si Photovoltaic modules are the most common in the market with high efficiency multi-junction cells promising a better future.

Photo voltaic (PV) modules are characterised by their fill factor, efficiency and rated power. Fill Factor (FF) is a measure of junction quality and series resistance and its value typically lies between 0.6 and 0.7 . For a cell that is reasonably efficient, the fill factor can be expected to be between 0.7 and 0.85 . The closer the FF is to unity the higher the quality of the PV module. With poorer quality cells, the difference in voltage between open circuit voltage and voltage at maximum power is greater, and hence the FF is reduced [2,3]. The light generated current depends linearly on the solar irradiation and is also influenced by the temperature according to the following equation

$$
\begin{gathered}
I s c=\left(I s c, n+K I^{*} \Delta T\right)^{*} G / G n \\
V o c=V o c, n+\left(K v^{*} \Delta T\right)
\end{gathered}
$$

Where Isc is the short circuit current, $\mathrm{G}$ is the irradiation on PV module, Gn is the nominal irradiation, Voc is open circuit voltage, $\Delta \mathrm{T}$ is the difference between actual and nominal temperature and $\mathrm{KI}$ is the short circuit current/temperature coefficient [4]. As can be seen from the equation, current generated increases with irradiation and temperature as $\mathrm{KI}$ is positive while Voltage decreases with increase in temperature as $\mathrm{Kv}$ is negative. Hence a balance needs to be struck between the level of solar irradiation and temperature of the panel as infrared radiation is an integral part of solar radiation.

A Concentrating Photovoltaic Technology (CPT) makes use of this theory of improvement in output with increased irradiation under controlled temperatures. The practicality of this idea has been tested but all of them made use of solar arrays designed from cells rather than an out of the market standard PV module [5-8]. At present there are many varieties of PV modules are in operation in the market and aim of the present work is to improve their output characteristics. In this context a solar radiation concentrating setup and a heat sink was designed, and its impact on the performance of an off the shelf PV Module was investigated.

\section{Experimental Setup}

The setup consists of a standard $18 \mathrm{~W}$ poly crystalline Si PV module in its aluminium casing and its specifications are as given in the Table.1 
Table 1. The parameters of the PV module at $1000 \mathrm{~W} / \mathrm{m} 2,25 \mathrm{OC}$ and AM 1.5 (STC)

\begin{tabular}{|c|c|c|c|}
\hline $\mathrm{P}_{\mathrm{m}}(\mathrm{W})$ & $\mathrm{V}_{\mathrm{OC}}(\mathrm{V})$ & $\mathrm{I}_{\mathrm{SC}}(\mathrm{A})$ & $\mathrm{FF}(\%)$ \\
\hline 18.06 & 21.6 & 1.06 & 78 \\
\hline
\end{tabular}

The edges of the casing were made leak proof by using a sealant. The junction box was isolated to ensure there was no short circuit once the casing was filled with water. Copper tubes of diameter $8 \mathrm{~mm}$ were then given a serpentine shape and placed inside the aluminium casing (Fig 1). A back cover was fabricated to prevent any vaporization of water from the enclosure due to direct solar radiation.

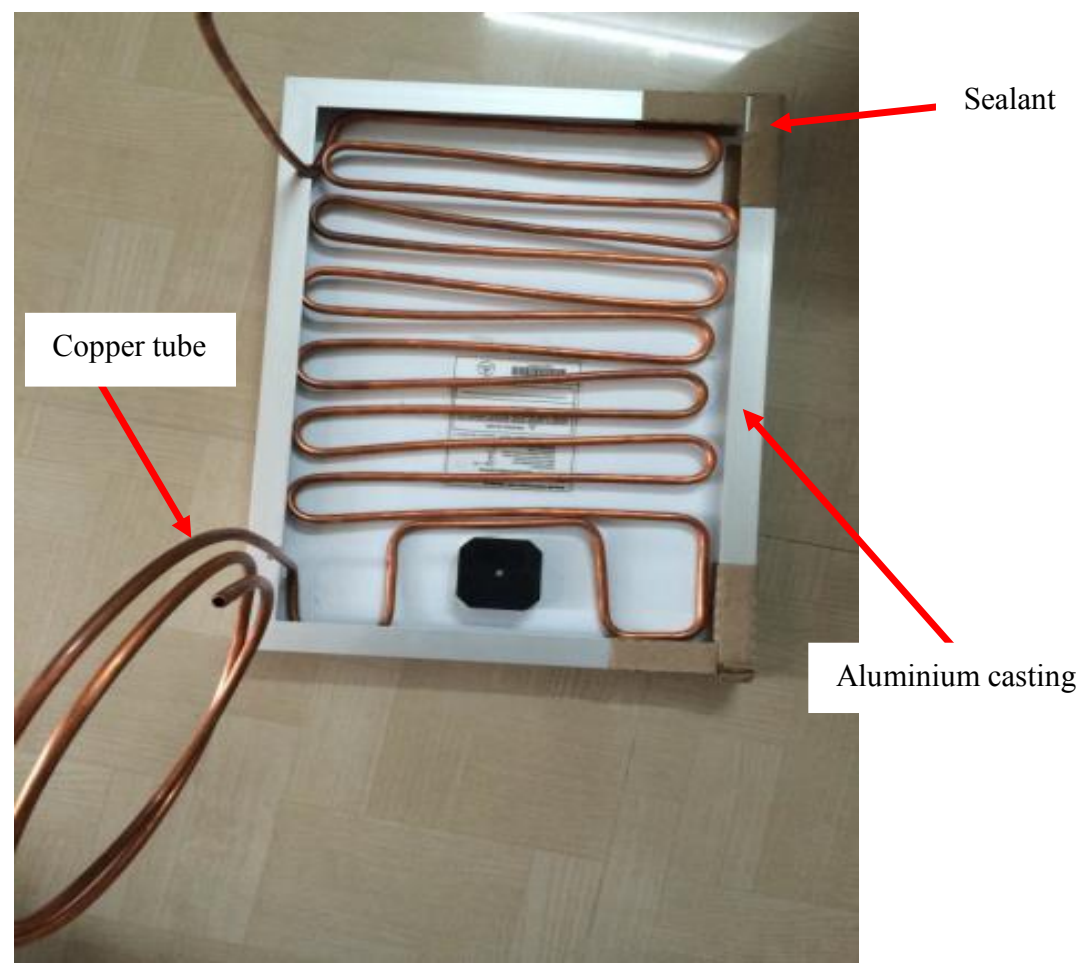

Fig. 1. Copper tubes behind the panel

The concentrator was fabricated using plywood from which three parabolic ribs measuring $1000 \mathrm{~mm}$ along the length were cut. The ribs were then spaced out at $250 \mathrm{~mm}$ from each other and supported by rectangular strips placed strategically at three locations. Rectangular strips of mirrors measuring $500 \mathrm{~mm}$ in width and 25.4 $\mathrm{mm}$ in length were then stuck along the parabolic profile to form the parabolic concentrator the focal point of which was $635 \mathrm{~mm}$ from the origin of the parabola. Two flat mirror reflectors of dimensions $500 \times 320 \mathrm{~mm}$ were placed at the flanks of the parabolic trough with provisions to adjust its inclination in two orthogonal planes 
as shown in figure 2. The parabolic trough and the two flat mirror reflectors were pivoted on a stainless steel pipe allowing them to be rotated along the width of the trough.

The PV module was supported at the corners and positioned at a height of $800 \mathrm{~mm}$ from the origin of the parabola to ensure that the entire PV module was lit by the sun and not just a segment. On the day of the experiment the aluminium casing was filled with water which was to serve the purpose of conducting the heat from the PV module to the copper tubes carrying water. One end of the copper tube was fed with water and the warmer water coming out of the other end was collected in a bucket. This formed the cooling mechanism in our concentrating setup.

\section{Performance Analysis of the Concentrated PV module}

The electrical performance of the concentrated PV module with water cooling is compared to a fixed PV module. At a particular time, readings are taken and currentvoltage characteristics are graphically represented. In order to measure the global solar radiation, a solar cell has been used. It is a known fact that the current output of solar cells is a linear function of solar irradiation. Also the current output of solar cell does not depend strongly on the temperature of the solar cell. Therefore solar cell current can be used as a measure of solar irradiation at a given time. Cell current or short circuit current of the module is proportional to Solar Irradiation

$$
\text { Solar Irradiation }(\mathrm{W} / \mathrm{m} 2)=K * \text { Cell Current }
$$

$\mathrm{K}$ is proportionality constant, obtained from the relationship between Solar Irradiation and Cell Current. The cell current is the short circuit current of the solar cell. Irradiation was measured using a standard cell, for which $\mathrm{K}=2175$.

Under concentrated conditions, the PV module receives more solar radiation as compared to the fixed PV module. Due to this the temperature of the CPV module rises. However, this rise in temperature is compensated by the cooling water passing through the copper tubes that carries away a considerable amount of heat from the module. 


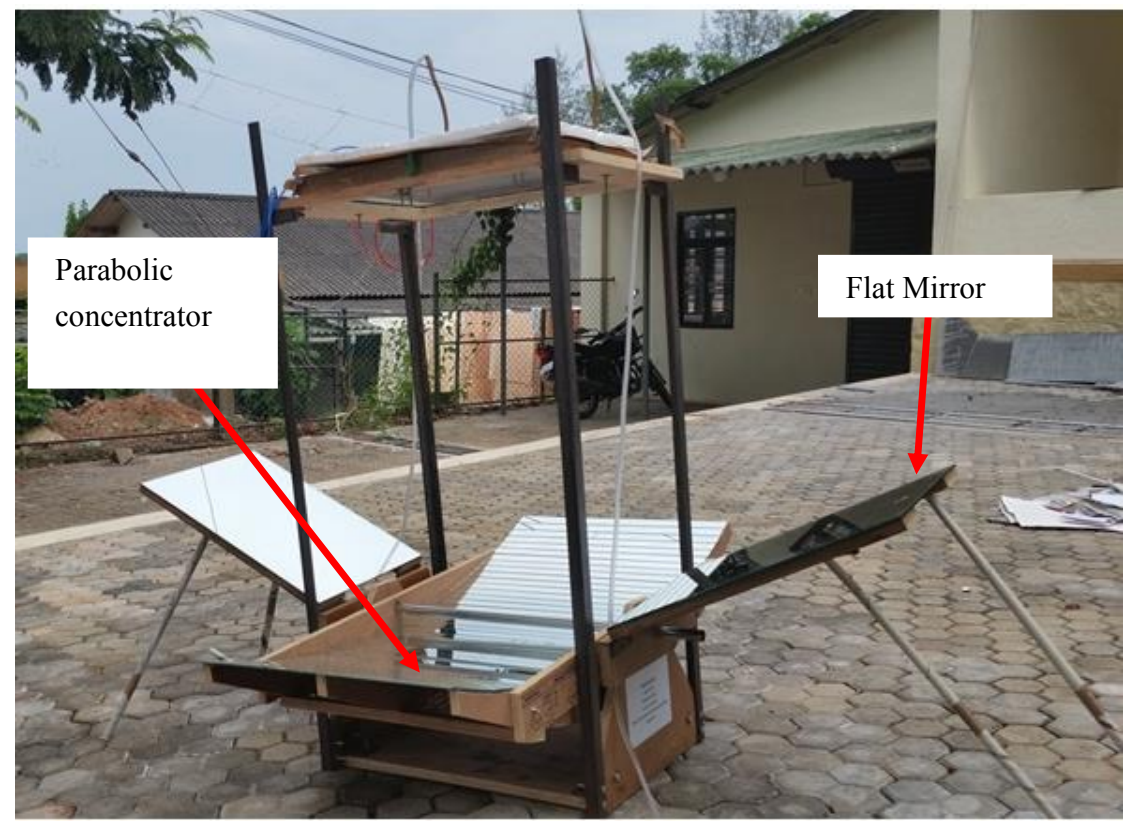

Fig. 2. Concentrated Hybrid Photovoltaic System

The performance of a solar cell is best indicated by its current-voltage characteristics. It is therefore important to know the output voltage and output current and how they vary with respect to each other and the surrounding environment. The current and voltage values for different cases shown are shown in figure 3. 


\section{V characterstics}

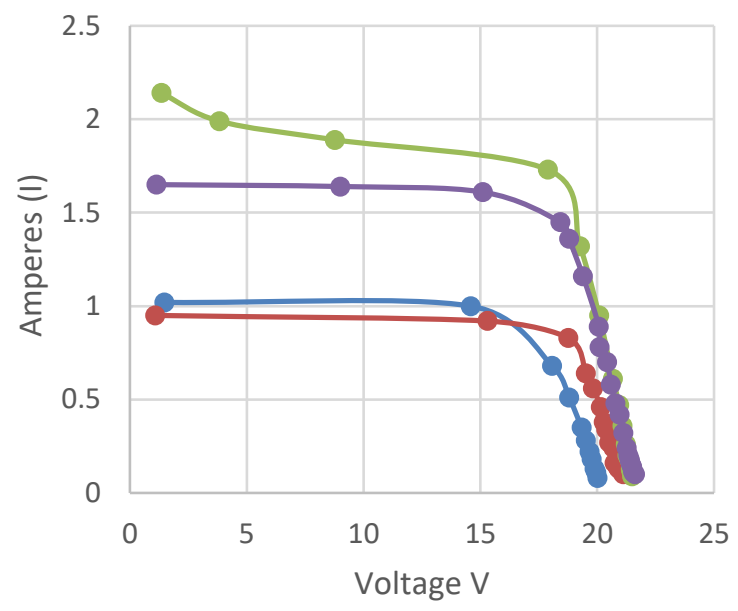

- Norma operating condition

- Normal operating condition with cooling

- concentarted operating condition with cooling on clear day

- concentrated operating condition with cooling on partially cloudy day

Fig. 3. Current Voltage characteristic of the PV module under different operating conditions

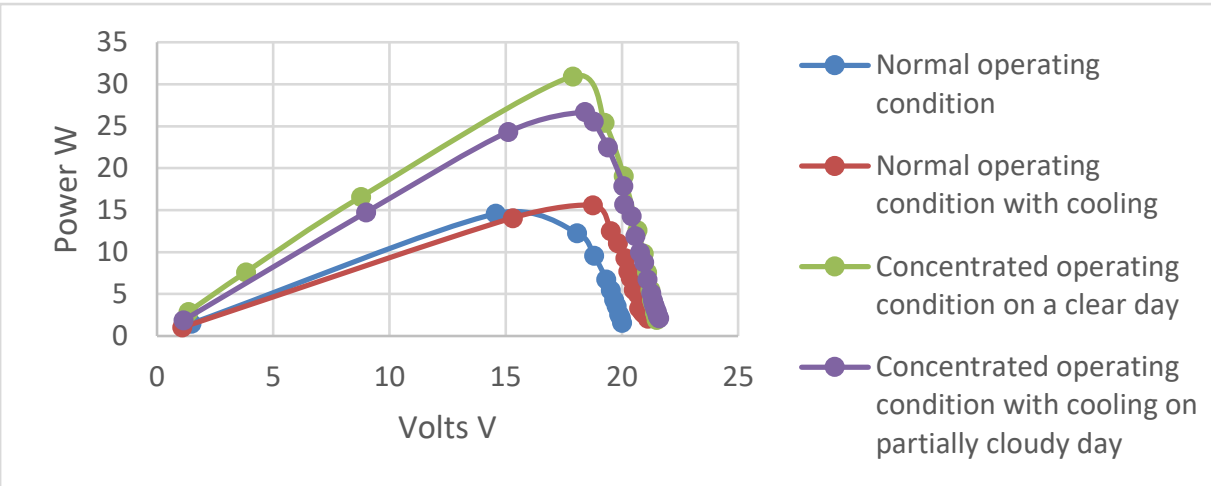

Fig. 4. Power Characteristic of the PV module under different operating conditions

Experimentation under concentration without cooling and with cooling shown an improvement in output current generated by the Concentrated PV module. However the electrical efficiency of this system is reduced. The maximum power produced from the CPV module under the influence of cooling was $30.94 \mathrm{~W}$, while the maximum the maximum power for a fixed PV module without cooling was $15.57 \mathrm{~W}$ as shown in figure 4. Comparing the CPV module and fixed PV module, it has been found that the output current of the CPV module was 2.1 times the fixed PV module. The electrical efficiency of the CPV module was $9.2 \%$ and of the fixed PV module was $12.63 \%$. The efficiency of both modules are decreased due to high cell 
temperatures. The solar radiation gain and output from the CPV system can be increased even further, but it could not happen in this experiment due to optical losses of the reflective mirrors, shadow losses due to gaps between the strip of reflective mirrors, the efficiency drop due to the temperature rise of the solar cell and uneven intensity of solar radiation while experiment was being performed.

\section{Conclusions}

In this work the performance of CPV module subjected to water cooling has been analysed and it is compared with a fixed PV module that is directly exposed to sunlight. It has been found that the output current increases by about 1.5 to 2.1 times, but its electrical efficiency is drops by $2-3 \%$. The CPV module was tested on a clear sunny day and also on a cloudy day. On a cloudy day, the maximum output current was lower, but it indicated a better VOC. This is due to temperature being a function of both voltage and current. On a cloudy day, as the module is subjected to a lower temperature, ISC decreases and VOC increases, in comparison to the CPV module on a sunny day.

\section{Acknowledgement}

We would like to express our deepest gratitude to Dr Jagannath K, Head department of Mechanical and Manufacturing Engineering for support and encouragement while carrying out this project. We are also deeply obliged to Mr Jayaraj, Dept. of Electrical and Electronics Engineering, MIT Manipal who has been instrumental in conducting the testing phases of the setup.

\section{References}

1. Farrington Daniels, "Solar Energy", 17th Annual Meeting, American Power Conference, Chicago. Ill., March 20-April 1, 1955.

2. L. El Chaar, L.A. lamont, N. El Zein, "Review of photovoltaic technologies", Renewable and Sustainable Energy Reviews 15 (2011) page 2165-2175

3. Global Sustainable Energy Solutions (GCES), "Grid-Connected PV Systems Design and Installation", First Edition India.

4. Marcelo Gradella Villalva, Jonas Rafael Gazoli, and Ernesto Ruppert Filho, "Comprehensive Approach to Modeling and Simulation of Photovoltaic Arrays", IEEE transactions on power electronics, vol. 24, no. 5, may 2009, page $1198-1208$

5. M. Li, G.L. Li, X. Ji, F. Yin, L. Xu, "The performance analysis of the Trough Concentrating Solar Photovoltaic/Thermal system", Energy Conversion and Management, vol. 52 (2011) page 2378-2383

6. Mohan Kolhea, Du Binb, and Eric Huc, "Water Cooled Concentrated Photovoltaic System", International Journal of Smart Grid and Clean Energy, vol. 2, no. 2, May 2013, page 159-163

7. Chengdong Kong, Zilin $\mathrm{Xu}$, Qiang Yao, "Outdoor performance of a lowconcentrated photovoltaic-thermal hybrid system with crystalline silicon solar cells", Applied Energy vol 112 (2013), page 618-625, Elsevier. 
8. Z. Farhana, Y.M. Irwan, R.M.N. Azimmi, A.R.N. Razliana, N. Gomesh, "Experimental Investigation of Photovoltaic Modules Cooling System", 2012 IEEE Symposium on Computers and Informatics, page 165-169. 